\title{
CDK/JAK2/FLT3 Inhibitor TG02 Citrate
}

National Cancer Institute

\section{Source}

National Cancer Institute. CDK/JAK2/FLT3 Inhibitor TG02 Citrate. NCI Thesaurus. Code C105851.

An orally bioavailable citrate salt form of TG02, a multi-kinase inhibitor for cyclin dependent kinase (CDK) subtypes 1, 2, 7 and 9, Janus-associated kinase 2 (JAK2), FMSrelated tyrosine kinase 3 (FLT3, FLK2, ST K1), with potential antineoplastic activity. Upon oral administration, CDK/JAK2/FLT3 Inhibitor TG02 binds to and inhibits the CDK subtypes, JAK2, and FLT3. T G02 also inhibits, to a lesser extent, TYK2, TYRO3, STAT 5 and P38delta. This may result in both an induction of apoptosis and an inhibition of tumor cell proliferation in cancer cells that overexpress these kinases. JAK2, often upregulated or mutated in a variety of cancer cells, mediates ST AT 3 activation and plays a key role in tumor cell proliferation and survival. CDKs are serine/threonine kinases that play key roles in the regulation of the cell cycle and cellular proliferation. FLT3, a class III tyrosine kinase receptor, is overexpressed or mutated in most B lineage and acute myeloid leukemias. 